\title{
A new species of Campylothorax (Collembola: Paronellidae: Paronellinae) from Northern Brazil
}

\author{
Inaura P. da Silva Santos ${ }^{1 *}$, Nikolas G. Cipola ${ }^{1}$, José W. de Morais ${ }^{1} \&$ Bruno C. Bellini $^{2}$ \\ 'Laboratório de Sistemática e Ecologia de Invertebrados do Solo, CBIO, Instituto Nacional de Pesquisas da \\ Amazônia. Avenida André Araújo 2936, Aleixo, Caixa Postal 478, 69067-375 Manaus, AM, Brazil. \\ 2Programa de Pós-graduação em Sistemática e Evolução, Departamento de Botânica e Zoologia, Centro de \\ Biociências, Universidade Federal do Rio Grande do Norte. Rodovia BR 101, Lagoa Nova, Campus Universitário, \\ 59072-970 Natal, RN, Brazil. \\ *Corresponding author. Email: inaura.pss@gmail.com
}

\begin{abstract}
Campylothorax viruaensis sp. nov., a new species of paronellid springtail from the Amazon Rainforest, state of Roraima, Brazil, is herein described and illustrated. The new species is characterized by: pale yellow body with dark blue pigment on abdomen III and IV; dorsal chaetotaxy presenting S5i macrochaeta on head, mesothorax with 6-8 macrochaetae in p1-4 complex; A5 as macro or microchaeta on abdomen IV; collophore anterior side with 4+4 anterior long chaetae; and mucro with five teeth. Other characteristics usually omitted in traditional descriptions for the genus are presented such as morphology of apical region of third and fourth antennal segments, labial papillae, chaetotaxy of subcoxae, collophore, abdomen $\mathrm{V}$ and ventral region of head. Trunk specialized chaetae (S-chaetae) are also presented. Campylothorax viruaensis sp. nov. is the fourth record of Campylothorax from Brazil, the second from the Brazilian Amazon Rainforest and the first from the state of Roraima.
\end{abstract}

KEY WORDS. Amazon Rainforest, detailed dorsal chaetotaxy, Paronellini, Roraima, taxonomy.

Campylothorax Schött, 1893 is a small genus of large epiedaphic paronellid springtails that are mostly found over dead litter and vegetation (BeLLinger et al. 2016). These animals are characterized by very long antennae (longer than body), well developed appendages, and particularly by a strong bending between an enlarged metathorax and abdomen I, which gives the genus its name (Mitra \& Dallai 1980, Mari Mutt 1987, BELLINGER et al. 2016).

Campylothorax currently comprises 12 described species which are restricted to the Neotropical and Ethiopian regions, with nine and three species, respectively (Soto-Adames 2016, BELLINGER et al. 2016). In Brazil, only three species have been recorded: C. cassagnaus Mitra \& Dalai, 1980, C. schaefferi Börner, 1906 and C. mitrai Bellini \& Meneses, 2012. Among the species cited above, only $C$. schaefferi had been previously found in Northern Brazil (ABRANTES et al. 2012).

Herein we describe a new species of Campylothorax from the Amazon Rainforest of the state of Roraima, Northern Brazil, and add new characteristics to the generic diagnosis.

\section{MATERIAL AND METHODS}

Specimens were collected with pitfall traps, preserved in $70 \%$ ethanol, clarified with potassium dichromate and hydrochloric acid, and mounted on glass slides with Arlé's liquid following the procedures described in ARLé \& MENDONÇA (1982). Habitus was photographed in ethanol gel using a DFC420 digital camera attached to a stereomicroscope. Photographs were digitally corrected using the Leica Application Suite V3.4.1. The overall morphology was described based on specimens of the entire type series. The dorsal chaetotaxy schemes follow SzEPTYCKI (1979), MItra \& Dalai (1980), Mari Mutt (1987), Soto-Adames et al. (2014) and Soto-Adames (2016); trunk specialized chaetae (S-chaetae) follow Zhang \& DehaRveng (2015); labial chaetotaxy follows GISIN (1964) and labial papilla follows FJELLberg (1999). Abbreviations used in the descriptions are: Ant, Abd and Th for antennae, abdomen and thorax segments, respectively. Type material is deposited at the Invertebrate Collection of Instituto Nacional de Pesquisas da Amazônia (INPA), Manaus, state of Amazonas, Brazil. 


\section{TAXONOMY}

\section{Campylothorax viruaensis Santos, Cipola \& Bellini, sp. nov.}

Figs. 1-29

urn:Isid:zoobank.org:act:EB822446-6341-4BCD-BDA8-B084251A9591

Description. Total length of holotype $2.48 \mathrm{~mm}$. Habitus typical of Campylothorax (Fig. 1). Specimens in ethanol pale yellow with dark blue pigment covering Ant I (completely), II (partially), part of head, anterior and lateral regions of Th II, latero-anterior region of Th III, legs, Abd III (almost completely), Abd IV (a large transversal band covering 2/3 centrally in the segment) and middle region of dens (Fig. 1). Brownish scales covering Ant I and II, basal halves of Ant III and IV, head, thorax, abdomen, legs and furcula. Collophore without scales. Dorsal head and trunk with reduced number of macrochaetae.

Head. Ant IV annulated, with smooth and ciliate chaetae and some blunt sensilla (Fig. 2). Ant III apical sense organ with 2 rods, 2 guard sensilla, surrounded by smooth and ciliate chaetae (Fig. 3). Eye patches oval, largest lenses A and B, smallest G and $\mathrm{H}$, with four interocular chaetae (Fig. 4). Maxillary palp with one smaller (about half length of a.s.) smooth basal chaeta (b.s.) (Fig. 5). Four prelabral and 14 (4/5/5) labral smooth chaetae, four anterior (a1 and a2), five median (m0, m1 and $\mathrm{m} 2$ ) and five posterior (p0, p1 and p2) (Fig. 6). Head ventral chaetotaxy as in Fig. 7, all post-labium chaetae ciliate. Basomedian and basolateral field with chaeta M1-M2, r, E, L1-L2, A1-A5 (Fig. 8). Labium with five smooth proximal chaetae. Labial palp with five papillae (A-E), A and C simple, B and D with 4 smooth appendages and $\mathrm{E}$ with lateral process (l.p.) smaller than the papilla and 4 smooth appendages (Fig. 9). Dorsal chaetotaxy (Figs. 4,10 ) with 11 antennal macrochaetae; 4 or 5 anterior macrochaetae (A0, A1, A2, A3 and A5), A1 as macro, microchaeta or totally absent; 5 sutural macrochaetae (S2, S3, S4, S5i and S5); 2 post-sutural chaetae, Ps 2 as microchaeta and Ps5 as mesochaeta; 2 post-occipital anterior chaetae, $\mathrm{Pa} 5$ as macrochaeta and $\mathrm{Pa} 6$ as bothriotrichum; posterior region with 3 microchaetae.

Thorax. Dorsal thorax chaetotaxy as in Figs. 11-12; legends to symbols as in Fig. 10. Th II posterior series 'p' with p1-4 postero-medial complex formed by 6-8 macrochaetae, arranged as typical for Campylothorax; p5, p6 and p6e as microchaetae; antero-lateral sensillum 'al' (S-chaeta) and microsensillum ' $m s^{\prime}$ (S-microchaeta) present (Fig. 11). Th III internal macrochaetae a5, a4, p3 and p2 present, antero-lateral sensillum 'al' (S-chaeta) present (Fig. 12). Legs. Subcoxa I with one macrochaeta and two pseudopores; subcoxa II with an anterior row (a) of 10 macrochaetae, posterior row (p) with five macrochaetae and two pseudopores; subcoxa III with a row of nine anterior plus three posterior macrochaetae and two posterior pseudopores (Figs. 13-15). Trochanter I with 11 anterior ciliate and four smooth chaetae (Fig. 16). Trochanteral organ with approximately 35 spine-like chaetae (Fig. 17). All ungues with four inner teeth,

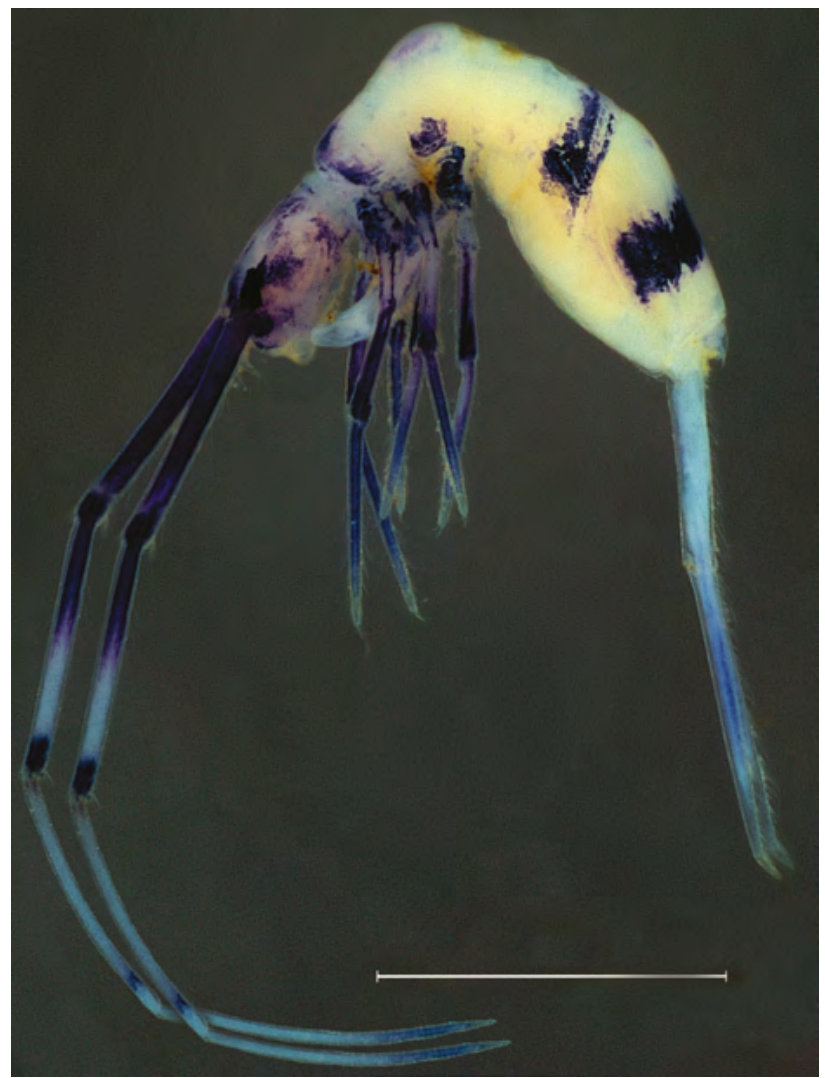

Figure 1. Campylothorax viruaensis sp. nov., habitus of a fixed specimen in ethanol. Scale bar: $1 \mathrm{~mm}$.

one pair at the basis, one medial and one smaller apical tooth; unguiculi trilamelate with two lamellae acuminate and one truncate, with smooth edges; tenent hair capitate, with smooth edges (Figs. 18-20).

Abdomen. Dorsal chaetotaxy as in Figs. 21-25; legends to symbols as in Fig. 10. Abd I medial series ' $\mathrm{m}$ ' with $\mathrm{m} 2, \mathrm{~m} 3$ and $\mathrm{m} 4$ as microchaetae; p6 as microchaeta, anterior microsensillum 'ms' (S-microchaeta) present (Fig. 21). Abd II bothriothricha m2 and a5 present, with four surrounding fan-shaped elements each; 6 and $\mathrm{m} 6$ as microchaetae; $\mathrm{m} 3$ and $\mathrm{m} 5$ as macrochaetae; medial sensillum 'as' (S-chaeta) near m3 (Fig. 22). Abd III bothriothrica $\mathrm{m} 2, \mathrm{~m} 5$ and a5 present, with two, four and six surrounding fan-shaped chaetae, respectively; m3, am6, pm6, p6, a7, m7, p7 plus one unnamed latero-posterior macrochaetae present; medial sensillum 'as' (S-chaeta) and microsensillum 'ms' (S-microchaeta) present (Fig. 23). Abd IV 'M' series with one macrochaeta and three microchaetae; 'A' series with A1 and A6 as macrochaetae and A5 as macro or microchaeta; ' $\mathrm{B}$ ' series with B3-B5 as macrochaetae; B6 as posterior bothriothricum; ' $\mathrm{C}$ ' series with $\mathrm{C} 2-\mathrm{C} 4$ as microchaetae; ' $\mathrm{T}$ ' series with $\mathrm{T} 2$ and $\mathrm{T} 4$ as bothriothrica with six and three surrounding fan-shaped elements, respectively, T5 as mesochaeta and T7 as macrochaeta, 


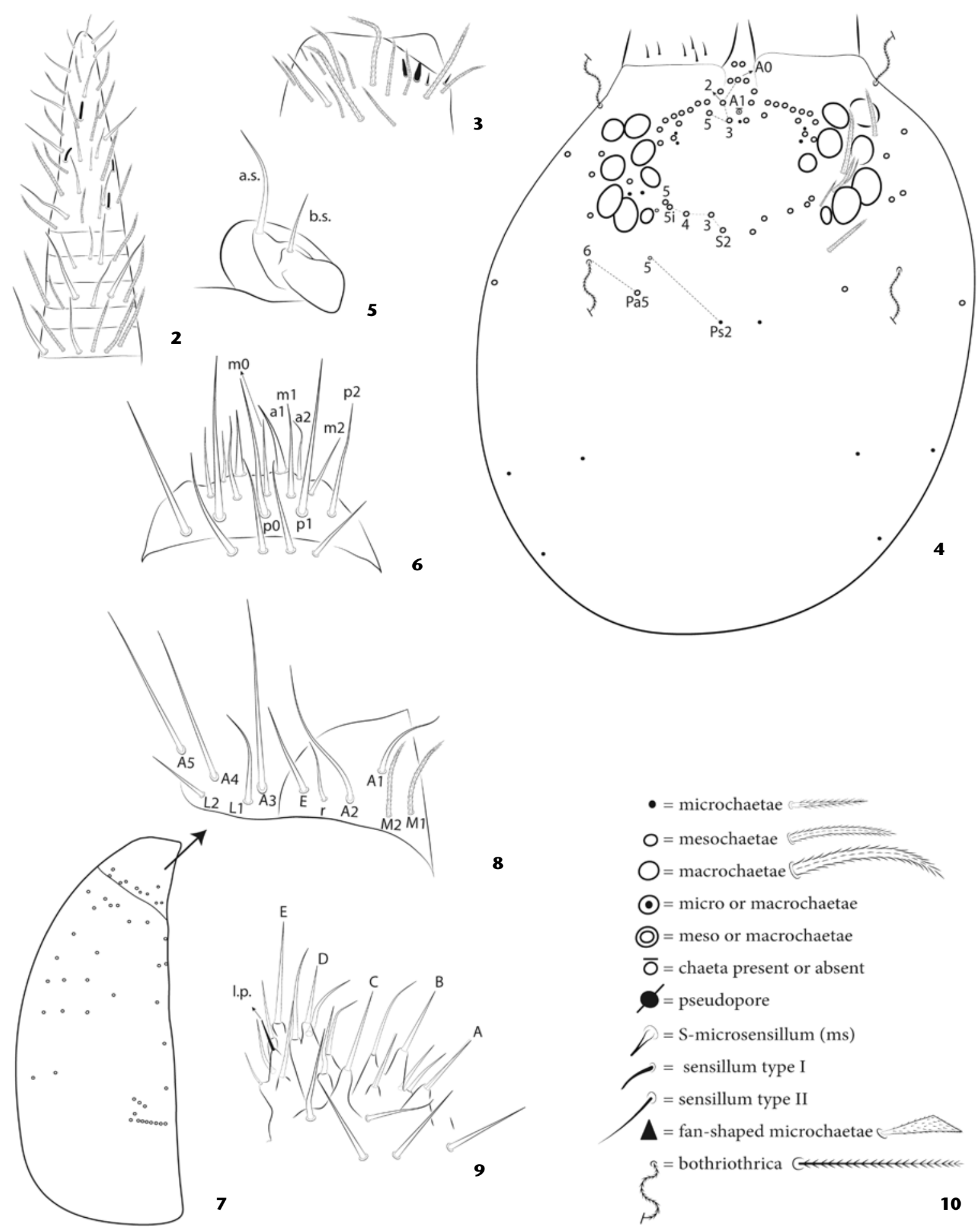

Figures 2-10. Campylothorax viruaensis sp. nov.: (2) antenna IV; (3) antenna III; (4) head dorsal chaetotaxy; (5) maxillary palp; (6) prelabral and labral chaetotaxy; (7) head ventral chaetotaxy; (8) labial region (left); (9) labial palp; (10) symbols used in detailed chaetotaxy schemes. 
13
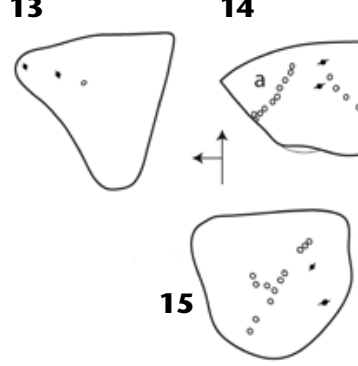

14
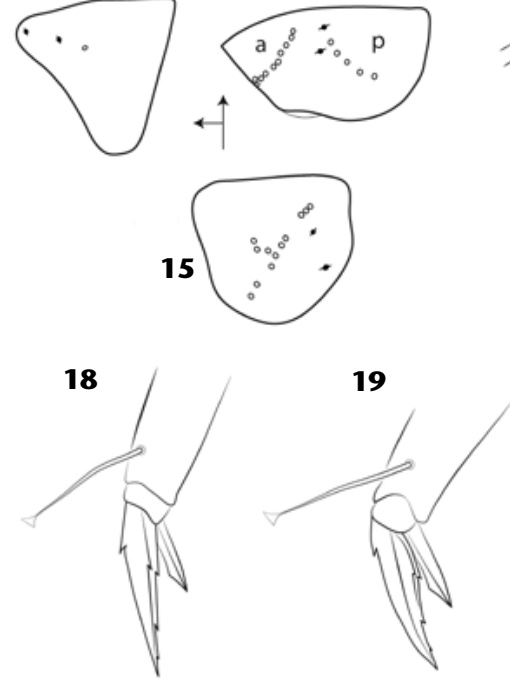

26

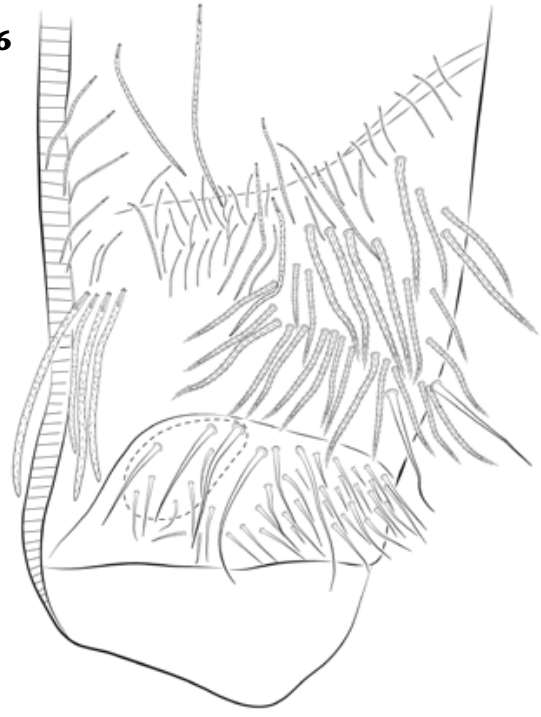

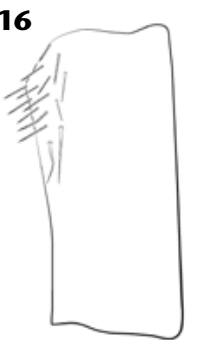

17

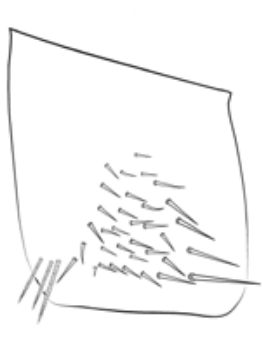

20
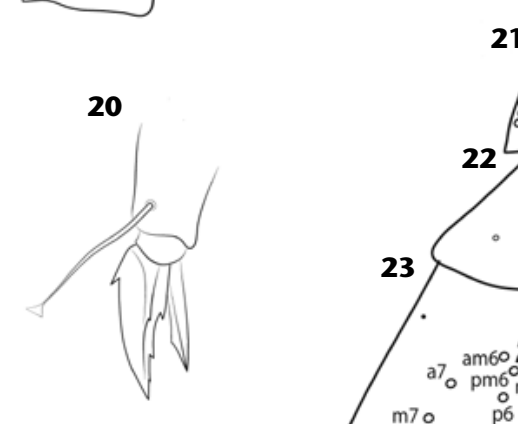

27
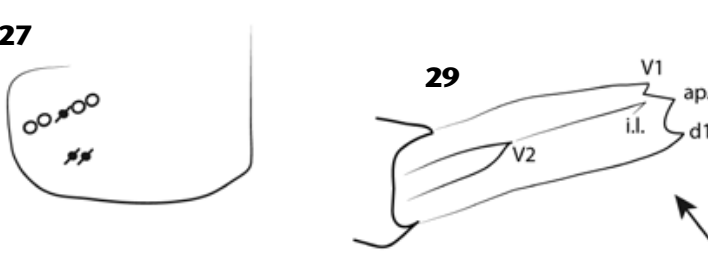

28

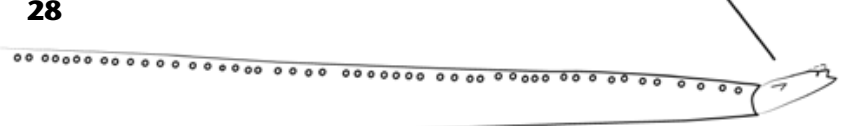

11 क000000000000<smiles>C1=C[As]C1</smiles>

mis P1-4 complex

$23^{\circ} \mathrm{e}$

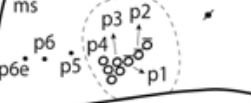

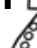
al
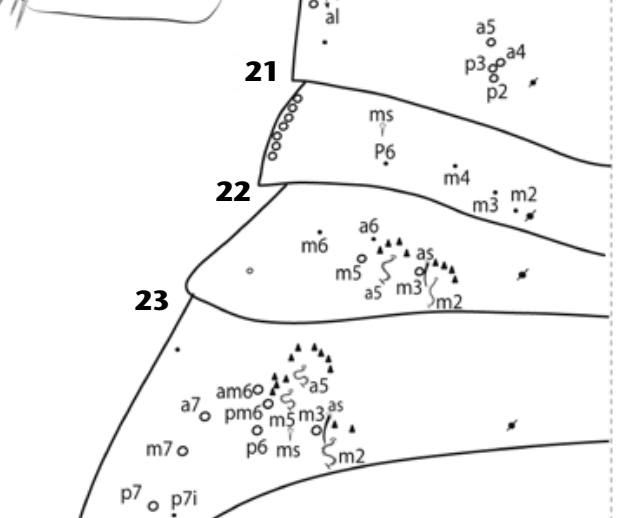

p7 $\circ$ pi
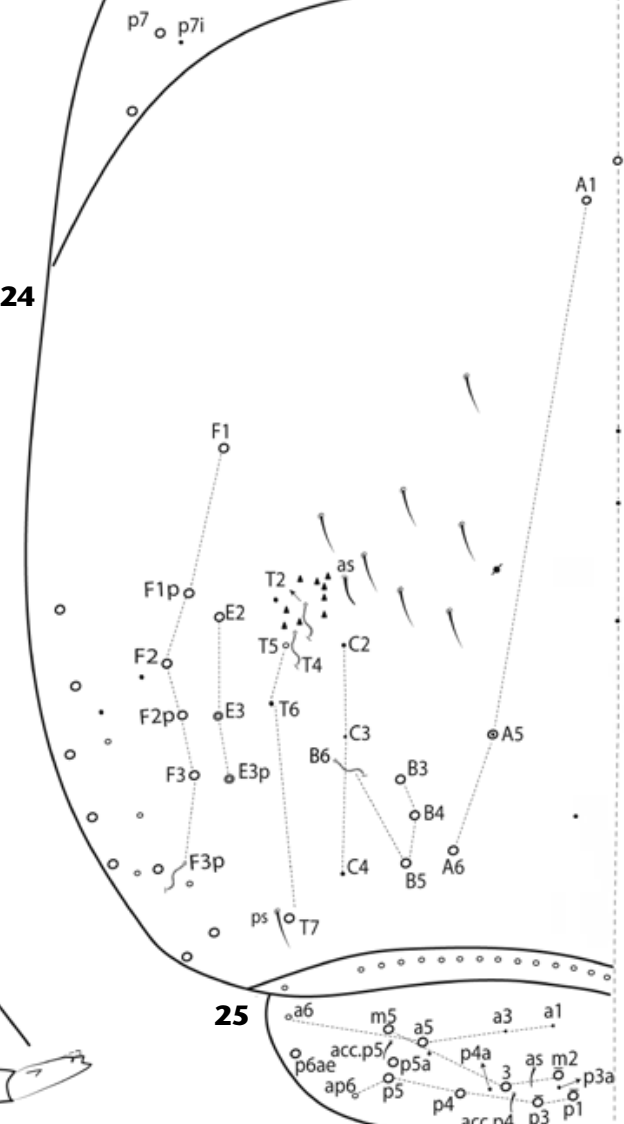

Figures 11-29. Campylothorax viruaensis sp. nov.: (11) mesothorax dorsal chaetotaxy; (12) metathorax dorsal chaetotaxy; (13) subcoxa I; (14) subcoxa II; (15) subcoxa III; (16) trochanter I; (17) trochanteral organ; (18) foot I complex; (19) foot II complex; (20) foot III complex; (21) abdomen I dorsal chaetotaxy; (22) abdomen II dorsal chaetotaxy; (23) Abdomen III dorsal chaetotaxy; (24) abdomen IV dorsal chaetotaxy; (25) abdomen V dorsal chaetotaxy; (26) collophore; (27) manubrial plate; (28) dental spines; (29) mucro. 
T6 as microchaeta; 'E' series with E2 as macrochaeta, E3 and E3p as meso or macrochaetae; ' $F$ ' series with F1-F3 as macrochaetae and F3p as bothriothricum; 14 lateral chaetae with uncertain homology (unnamed) and posterior region with about 15 mesochaetae (Fig. 24). One anterosubmedial sensillum 'as' type I (S-chaetae), seven central unnamed sensilla type II plus one posterior sensillum 'ps' (Fig. 24). Abd V anterior series ' $a$ ' with a1 and a3 as microchaetae, a5 as macrochaeta, a 6 as mesochaeta; medial series ' $\mathrm{m}$ ' with $\mathrm{m} 2$ (present or absent), $\mathrm{m} 3$ and $\mathrm{m} 5$ as macrochaetae; posteroanterior series ' $\mathrm{pa}^{\prime}$ with $\mathrm{p} 3 \mathrm{a}$ and $\mathrm{p} 4 \mathrm{a}$ as macrochaetae, p5a and p6ae as macrochaetae; posterior series 'p' with p1, p3 (present or absent), p4 and p5 as macrochaetae, and ap6 as mesochaeta; sensilla 'as', 'acc.p4' and 'acc.p5' type I present (Fig. 25). Collophore. Anterior side with 4 long slightly ciliate chaetae plus eight small proximal chaetae; latero-distal flap with approximately 38-46 smooth chaetae, eight more anterior chaetae present or absent (circled in Fig. 26), 40 slightly ciliate plus 27 ciliate chaetae on proximo-lateral side (outside flap); posterior side with 2 smooth chaetae (Fig. 26). Furcula. Manubrial plate (dorso-distal region) with 4 ciliate chaetae and 3 pseudopores (Fig. 27). Dens with one row of 41-50 ciliate spines (Fig. 28). Mucro typically elongated with five teeth, one basal tooth and four apical teeth (d1, ap., v1, v2 and i.l.) (Fig. 29).

Material examined. Holotype female, on slide number COLLE 055/INPA, BRASIL, Roraima: Caracaraí (Parque Nacional de Viruá, 1.486667N, 61.047778 W), 21.ix-9.x.2012, pitfall-trap, I.P.S. Santos coll. Paratypes: 4 males and 2 females on slides COLLE 055A-F/INPA, same data of the holotype. Paratypes: 5 males on slides COLLE 055G-K/INPA, same data of the holotype, except 16.i-6.ii.2013.

Distribution and habitat. Specimens of C. viruaensis sp. nov. were collected within the Amazon Rainforest and campinarana of Viruá National Park, state of Roraima, Brazil, which are included in Good's biogeographic zones 25 and 26, Neotropical Region, high and lowlands of Northern Brazil (Good 1974). The climate of the area is Equatorial (af), fully humid, characterized by seasonal flooding in lower zones (Коттек et al. 2006). The specimens were found in litter of dry and previously flooded forests during the dry season.Etymology. The species name is after its type locality, National Park of Viruá.

Remarks. The dorsal chaetotaxy and body pigmentation of C. viruaensis sp. nov. resemble C. sabanus (Wray, 1953) from Puerto Rico and C. cubanus Gruia, 1983 from Cuba. The new species differs from both in dorsal head chaetotaxy, with S5i macrochaeta (as microchaeta in C. sabanus and absent in $C$. cubanus). Abd IV central-posterior macrochaetae (4-5 in the new species, 6 in others), and 8 latero-posterior macrochaetae on series ' $\mathrm{E}$ ' to 'F' (6 in the other two species). Campylothorax sabanus also presents a distinct labial chaetotaxy when compared to the new species: L2 is extremely reduced (see MARI-MuTT 1987: 415), while in the new species L2 is only a little smaller. Regarding the collophore anterior side, C. cubanus and C. sabanus present $3+3$ anterior long chaetae, while $C$. viruaensis sp. nov. presents $4+4$.
Concerning the color pattern, the new species differs especially in Abd IV pigmentation. It only presents a transversal band of dark pigment in its middle region, while $C$. sabanus has almost all the second half of Abd IV pigmented, including the distal region. Campylothorax schaefferi presents a similar color pattern to C. viruaensis sp. nov., especially regarding Abd IV (with one transversal band of pigment), but the two species are different in the number of mucronal teeth (four in C. schaefferi, five in C. viruaensis sp. nov.) (Mitra \& Dallai 1980). Several other morphological features of $C$. schaefferi are currently unclear and a redescription of it with observation of ventral head and whole dorsal chaetotaxy is in need to rightly compare this species with other Neotropical taxa.

\section{ACKNOWLEDGMENTS}

We thank CNPq (project 474867/2011-0) for financing the sampling at Viruá National Park; CAPES Pro-Equipamentos for laboratory founding; Neusa Hamada/CNPq and Laboratório de Sistemática e Ecologia de Invertebrados do Solo (Elizabeth F. Chilson), CBIO, INPA, both for logistic support of images. The first author is granted by CAPES, CNPq and FAPEAM (project 062.00702/2015). The second author is granted by CNPq. The senior author is granted by $\mathrm{CNPq} /$ Programa de Pesquisa em Biodiversidade, Invertebrados (PPBio).

\section{LITERATURE CITED}

Abrantes EA, Bellini BC, Bernardo AN, Fernandes LH, Mendonça MC, Oliveira EP, Queiroz GC, Sautter KD, Silveira TC, Zeppelin D (2012) Errata Corrigenda and update for the "Synthesis of Brazilian Collembola: an update to the species list." Abrantes et al. 2010, Zootaxa 2388: 1-22. Zootaxa 3168: 1-21.

Arlé R, Mendonça C (1982) Estudo preliminar das espécies de Dicranocentrus Schött, 1893, ocorrentes no Parque Nacional da Tijuca, Rio de Janeiro (Collembola). Revista Brasileira de Biologia 42: 41-49.

Bellinger PF, Christiansen KA, Janssens F (2016) Checklist of the Collembola of the World. Available online at: http://www. collembola.org [Accessed: 13/04/2016]

Bellini BC, Meneses LF (2012) A new species of Campylothorax (Collembola: Entomobryoidea: Paronellidae) from the state of Alagoas, Brazil. Zoologia 29: 451-454. doi: 10.1590/S198446702012000500008

FJellberg A (1999) The labial palp in Collembola. Zoologischer Anzeiger 237: 309-330.

Gisin H (1964) Collemboles d'Europe. VII. Revue Suisse de Zoologie 71: 649-678.

Good R (1974) The geography of flowering plants. London, Longman Group, 574p.

GruiA M (1983) Collemboles arthropléones de Cuba récoltés par les expéditions cubano-roumaines en 1969-1973. Academia Republicii Socialiste România 4: 191-205. 
Kottek M, Grieser J, Beck C, Rudolf B, Rubel F (2006) World map of the Köppen-Geiger climate classification updated. Meteorologische Zeitschrift 15: 259-263. doi: 10.1127/09412948/2006/0130

Mari MutT JA (1987) Puerto Rican species of Paronellidae (Insecta: Collembola). Caribbean Journal of Science 23: 400-416.

Mitra SK, Dallai R (1980) Studies of the genus Campylothorax Schött, 1893 (Collembola Entomobryidae Paronellinae) with the description of a new species from Zaire. Monitore Zoologico Italiano 13: 273-321.

SzePTYCKI A (1979) Chaetotaxy of the Entomobryidae and its phylogenetical significance. Morpho-systematic studies on Collembola. IV. Warszawa, Polska Akademia Nauk, Zaklad Zoologii Systematycznej i Doswiadczalnej, Panstwowe Wydawnictwo Naukowe, 219p.

Soto-Adames FN (2016) Chaetotaxy of first-instar Campylothorax sabanus (Wray), and description of three new Campylothorax species from Hispaniola (Collembola, Paronellidae). Journal of Natural History 50: 1-30. doi: 10.1080/00222933.2016.1145272

Soto-Adames FN, RAfael J, Baquero E (2014) Comparative analysis of the dorsal chaetotaxy of Troglopedetes, Trogolaphysa, and
Campylothorax supports the synonymization of tribes Paronellini and Troglopedetini (Collembola: Paronellidae). Journal of Insect Science 14: 1-16. doi: 10.1093/jisesa/ieu140

Zhang F, Deharveng L (2015) Systematic revision of Entomobryidae (Collembola) by integrating molecular and new morphological evidence. Zoologica Scripta 44: 298-311. doi: $10.1111 /$ zsc. 12100

Submitted: 25 January 2016

Received in revised form: 20 April 2016

Accepted: 8 May 2016

Editorial responsibility: Gabriel L.F. Mejdalani

Author Contributions: IPSS wrote the paper and drew the pictures. NGC supervised the description, took the picture of specimen fixed in ethanol, drew the pictures and reviewed all the drawings and paper. BCB reviewed all drawings and paper. JWM reviewed all paper.

Competing Interests: The authors have declared that no competing interests exist. 